\title{
Cultivating Men's Interest in Family Planning in Rural El Salvador
}

\author{
Rebecka I. Lundgren, James N. Gribble, Margaret E. Greene, Gail E. Emrick, \\ and Margarita de Monroy
}

\begin{abstract}
A pilot project in rural El Salvador tested the integration of family planning into a water and sanitation program as a strategy for increasing male involvement in family planning decisionmaking and use. The organizations involved posited that integrating family planning into a resource management and community development project would facilitate male involvement by diffusing information, by referring men and women to services, and by expanding method choice to include the new Standard Days Method through networks established around issues men cared about and were already involved in. This article examines data from a community-based household survey to assess the impact of the intervention and finds significant changes in contraceptive knowledge, attitudes, and behavior from baseline to endline. Because the differences between baseline and endline are greater than the differences between participants and nonparticipants at endline, the study demonstrates the power of informal networks for spreading information. (STUDIES IN FAMILY PLANNING $2005 ; 36[3]: 173-188)$
\end{abstract}

In widely divergent settings, from El Salvador to Ethiopia, the models for family planning and reproductive health-care service delivery are remarkably similar. Services are typically aimed at women, and rarely is much effort made to educate or involve men. Even in settings where methods that involve men are emphasized, such as Bolivia, Pakistan, and Turkey, the promotion of family planning has not focused on creating male interest and involvement. One unfortunate consequence of this common model of reproductive health has been to reinforce the idea of family planning as women's responsi-

\footnotetext{
Rebecka I. Lundgren is Director of Operations and Behavioral Research, Institute for Reproductive Health, Georgetown University, 4301 Connecticut Avenue, NW, Suite 310, Washington, DC 20008. James N. Gribble is Senior Scientist, Futures Group, Washington, DC. Margaret E. Greene is Director, Center for Global Health, George Washington University, Washington, DC.

Gail E. Emrick is Technical Advisor for Central America, Project Concern International El Salvador, San Salvador, El Salvador. Margarita de Monroy is Regional Coordinator for Central America, Institute for Reproductive Health, Georgetown University, Santa Tecla, El Salvador. E-mail:lundgrer@georgetown.edu.
}

bility, leaving little or no role for men (Greene and Biddlecom 2000).

During the past 15 years, many in the reproductive health field have come to appreciate the need for the constructive involvement of men in programs and services. The 1994 International Conference on Population and Development (ICPD) held in Cairo articulated why and how male involvement should occur. Recognition is growing that men are interested in and need reproductive health information and services, both for their partners and for themselves (Drennan 1998; Ringheim 2002; AGI 2003), and that the reproductive health of individuals depends heavily on the relationship between the two people concerned. Awareness has increased that services should be directed not only toward women but also toward men and couples (Becker 1996; Ringheim 2002).

A challenge confronting the redirection of family planning services toward greater male involvement and couples' collective decisionmaking is how to enlist the participation of men effectively. Given that men tend to obtain much of their reproductive health information from peers (PAHO 2002), a promising new program strategy is to promote the diffusion of information through informal networks. A few pilot projects have begun to reach men through existing networks by incorporating family planning information and referrals into development activities outside the health field such as agricul- 
tural extension and environmental programs (Foreit et al. 1998; Population Council 1998; Sealza and Costello 1998). Large-scale expansion of this strategy, however, has not yet occurred. This article describes one such pilot project in El Salvador.

Despite progress in recent years, few family planning programs involving men have been documented effectively or evaluated. The effort to reach out to men in the context of a broader development effort holds promise, especially in countries where traditional gender roles and divisions prevail, where reproductive health remains a "women's concern," and where gender inequities impede spousal support and communication.

Like most family planning programs around the world, El Salvador's program predominantly serves women. Although the Ministry of Health's five-year plan (1999-2004) for sexual and reproductive health refers to the range of issues highlighted at ICPD, it avoids explicitly calling for male involvement in reproductive health, which is one of the Programme of Action's salient mandates. In the absence of guidelines and training, programs and providers are likely to exclude men from routine services. Indeed, family planning literature consistently reports that men are marginalized in family planning services. The literature also documents providers' bias against male clients, manifested as a failure to welcome men, to provide them with accurate information, and to protect their rights to privacy and confidentiality (Skibiak 1993; Ringheim 2002).

This article examines a program pioneered by a nongovernmental organization (NGO) called Project Concern International (PCI) designed to increase men's involvement in family planning through activities not related to the health program. This initiative was consistent with PCI's mission to prevent disease, improve community health, and promote sustainable development through dynamic partnerships that build local capacity in efficient and measurable ways. In collaboration with the Institute for Reproductive Health of Georgetown University and the El Salvadoran Ministry of Health, Project Concern International and its local El Salvador affiliate PROCOSAL (Programas Comunitarias para El Salvador) tested the integration of family planning counseling into its water and sanitation program in 13 villages. PROCOSAL is part of a national network of organizations working in water and sanitation. PROCOSAL works in nine of the 14 departments of El Salvador: Zona Sur of San Salvador, Chalatenango, Cuscatlan, La Paz, San Vicente, San Miguel, Cabañas, Usulután, and La Libertad. The purpose of this initiative was to increase male involvement in family planning decisionmaking and practice, a domain traditionally reserved for women. The initiative also sought the integration of women into water committees, a domain previously reserved for men. The intervention study was developed to facilitate couples' communication and joint decisionmaking regarding family planning.

The objective of this study was to assess the feasibility of incorporating family planning education and provision of the Standard Days Method ${ }^{\mathrm{TM}}$ (SDM) into water and sanitation programs and to test the impact of these interventions on male participation and contraceptive knowledge and use.

\section{Project Concern International and Family Planning}

Although contraceptive prevalence in El Salvador has doubled during the past 25 years, the method mix continues to be dominated by female sterilization (see Table 1). The male methods used-including condoms, withdrawal, periodic abstinence, and the Billings methodremain a relatively insignificant part of the mix. Moreover, unmet need for family planning - the proportion of women who do not want to become pregnant for the next two years, but who are not using a contraceptive method-remains high, especially in rural areas (ADS et al. 1987 and 2004).

Since beginning its work in El Salvador in 1994, PCI has become increasingly convinced that access to family planning is critical to sustainable development. In El Salvador, population density has reached 384 persons per square mile, and the natural resource base is ever shrinking (Ministerio de Economía 1995). PCI perceives a close relationship between resource management, community development, and family planning, and has identified the inability of couples to plan their families as a major concern in the communities where PCI works.

PCI works closely with community-development organizations to construct water and sanitation systems

Table 1 Percentage of women reporting contraceptive use, by method, El Salvador, 1987 and 2002

\begin{tabular}{lrr}
\hline Method & $\mathbf{1 9 8 7}$ & $\mathbf{2 0 0 2}$ \\
\hline Female sterilization & 18.0 & 32.7 \\
Oral contraceptive & 8.7 & 5.8 \\
Injectable & - & 18.3 \\
Condom & 1.4 & 2.9 \\
Periodic abstinence/Billings & 1.7 & 2.9 \\
Withdrawal & $a$ & 2.6 \\
Other & 4.2 & 2.2 \\
Total & 34.1 & 67.4 \\
\hline - = Not applicable. $\quad$ ancluded in "other." & & \\
Source: ADS et al. 1987 and 2004. & &
\end{tabular}


and provide health education. Each of these organizations, called ADESCOs (Asociaciones para el Desarollo Comunitario), establishes a health committee responsible for providing health education to the community. PCI facilitators visit each community weekly to provide education to community groups and to train and supervise health volunteers. Project activities include orienting water boards, training volunteers, providing group talks by PCI facilitators and by the Ministry of Health $(\mathrm{MOH})$ promoters, and directing volunteers to conduct home visits. Group talks offer information about management of environmental resources such as water and soil and about latrines. These topics are also discussed during home visits, which are intended to reinforce behavioral change in sanitation practices. PCI staff coordinate activities with $\mathrm{MOH}$ staff and promoters in each of the communities where they work. After the construction of water and sanitation systems - which takes about 12 months-is completed, PCI leaves the community and the ADESCO assumes responsibility for maintenance of the system.

After consulting with community-development boards regarding the integration of family planning counseling into their activities, Project Concern International learned that some community members rejected available hormonal family planning methods but expressed interest in using natural methods. The boards were interested in providing information to men to help overcome their opposition to practicing family planning. PCI conducted research to better understand the reasons for the communities' unmet need for family planning. The researchers found that the practice of periodic abstinence was common, especially after the use of other methods had been discontinued, although few individuals could identify their fertile days correctly (Monroy 2000). Results of interviews with men and women with unmet need suggested that some men were opposed to the use of modern methods, either because of concerns about their side effects or because they felt that contraceptive use would encourage their wives to be unfaithful. In a survey conducted in the department of Chalatenango, one of the study areas, 15 percent of women surveyed reported that they do not use a family planning method because they are concerned about side effects. Twelve percent mentioned that they would prefer to use a natural method. Results are similar in other study departments (ADS 2004).

PCI determined that offering a particular family planning method that is based on fertility awarenessknown as the Standard Days Method-in addition to condoms would be a feasible strategy for overcoming this resistance. The Standard Days Method is a fertility- awareness method of family planning developed by researchers at Georgetown University for women who have regular cycles lasting from 26 to 32 days in length. Women with cycles in this range have a fertile window between days 8 and 19, and couples wishing to avoid pregnancy are directed to avoid unprotected intercourse on these days. Users of the Standard Days Method typically rely on CycleBeads ${ }^{\mathrm{TM}}$, a string of 32 color-coded beads, to identify their fertile days and to monitor cycle length. Use of CycleBeads also facilitates communication between partners about the management of fertile days. An international clinical efficacy trial showed the SDM to have a failure rate of less than 5 per 100 woman-years of correct use and a typical failure rate of 12 per 100 woman-years of use. This rate is comparable to failure rates of other user-dependent methods such as the male condom, which has failure rates for correct and typical use of 2 and 15 percent, respectively (Arévalo et al. 2002; Hatcher 2004). ${ }^{1}$ PCI hoped that men would respond positively to this new method, not previously taught in El Salvador. In fact, SDM was presented publicly for the first time by community volunteers during this study. Community-based programs in other countries have since adopted the training methodology and the materials that were developed for providers and clients of low literacy during this project (Gribble 2003).

An important element of PCI's effort to expand men's access to information and services was the diffusion of its message through informal channels. PCI staff observed that although health and sanitation information spread rapidly through their volunteer network, family planning information provided by the $\mathrm{MOH}$ spread much less rapidly, perhaps because the topic was rarely discussed openly in the community. PCI set out to provide a framework to make the discussion of family planning and related topics more acceptable and commonplace. The organization did not seek to replace existing family planning services; rather its goal was to supplement them, in part by strengthening links between the community and the health system.

During clinical trials, the Institute observed that information about the Standard Days Method sometimes diffused throughout the community by word of mouth without a trained provider serving as an intermediary. Because the method does not require the use of contraceptive supplies and is simple to understand, some users felt confident about teaching others how to use the method. Thus, including SDM in the intervention encouraged informal networks to spread family planning information through the community.

The project offered some unique opportunities for success. First, as a nongovernmental organization with 
credibility in the community, Project Concern International was enabled by its strong reputation to extend its work into the domain of family planning. Second, the initiative was consistent with PCI's institutional vision, which explicitly identifies gender inequities as an obstacle to sustainable development. The rationale for involving men in family planning as an extension of PCI's efforts to involve women in community-development boards made sense to leaders in the organization and to community leaders as well. As PCI began its work in family planning, it was challenged to include men in reproductive health programs.

Third, PCI's work in water and sanitation systems made it "male friendly," especially in comparison with most family planning organizations. PCI staff were relatively free of the biases held by many health workers with regard to men's roles in family planning. Staff and volunteers were comfortable and experienced in working with men; about two-thirds of the PCI staff were male. They had implemented previous project activities through community organizations with extensive male memberships.

PCI was able to link the already-valued concept of protecting natural resources with the concept of protecting family health by means of spacing births. The organization's planners hypothesized that integrating family planning discussion into a resource-management and community-development project would facilitate male involvement by linking family planning information and services with issues men already care about. They were able to relate the regenerative capacity of the environment to the reproductive health of women and men. For example, images used to raise awareness in the community equated fertile cycles on the land with the fertile cycles of women. As a result of highlighting this relationship, local staff and volunteers came to view the incorporation of men into family planning decisionmaking as a natural extension of their commitment to including women in decisionmaking in all development efforts. This approach proved to be a convincing rationale for the integration of family planning into watersystem projects among staff and potential clients.

\section{Designing the Initiative}

PCI developed and tested a model of family planning provision called "Planning Together," the title emphasizing gender equity in decisionmaking. The strategy included integration of family planning messages into water and sanitation education; community-based provision of condoms; introduction of the Standard Days Method; and referrals for other methods. Recognizing that men learn about family planning from their peers and from the mass media rather than from formal health-care providers, PCI set out to reach men through informal community networks. Their strategy was designed to encourage positive attitudes toward family planning and male involvement by spreading information through community leaders. Development and testing of the models took place during a four-month period, beginning in September 2000. Pretesting of models and validation of materials took place in the departments of La Paz and Cabañas, where PCI had water and sanitation projects that were not included in the study.

The family planning work was structured in a way similar to the organization's water and sanitation systems work. Condoms and SDM instruction were provided by volunteers trained and supervised by PCI field workers. Male and female staff and volunteers participating in the project were included in the development and testing of educational materials and methodologies. The project also was designed to strengthen the referral system between PCI and Ministry of Health clinics. PCI incorporated family planning information into the group talks provided by its facilitators and added two home visits on family planning topics to the three visits mandated by their heath-education strategy. It had developed this widely used methodology in collaboration with a network of NGOs and other public institutions in El Salvador with United Nations Children's Fund (UNICEF) support. This strategy, called the Water and Sanitation Family Visit, used as a basis for family planning education, was selected to enhance the potential for scaling up the intervention if it proved successful.

PCI developed its intervention based on prior research designed to explore the role of family planning providers, most of whom were Ministry of Health employees. In-depth interviews were conducted with 30 $\mathrm{MOH}$ health-care providers, all of whom were potential providers of information and services for men. Interviews were evenly distributed between professional health-care promoters (mostly male outreach workers), physicians, nurses, and traditional birth attendants. In addition, PCI hired a consultant to conduct focus-group discussions with $\mathrm{MOH}$ and PROCOSAL staff. Community-level focus-group discussions and individual interviews were conducted with opinion leaders and with men and women involved in PCI activities. The results of this research suggested that integrating family planning counseling into water and sanitation programs would be feasible and that family planning would be more acceptable when presented jointly to couples. Both men and women expressed interest in collective deci- 
sionmaking and increased communication about family planning. According to baseline survey results, for example, when asked whether they would like to receive family planning services individually or with their partner, 65 percent of women and 80 percent of men answered "together." PCI used these findings to design an outreach strategy and educational messages for incorporating family planning into their programs. Although from the outset this program had the clear potential to be an effective means of reaching men, one serious question lingered: Would a water and sanitation program provide a good platform for a family planning program? PCI posited that the water and sanitation program structure would provide an informal network for diffusing information about family planning. Capitalizing on existing networks was essential because research indicates that informal social networks can be a powerful mechanism for changing attitudes and behaviors regarding family planning (Kinkaid 2000).

Interviews and focus-group discussions with clinical and community health-care providers revealed that providers viewed men as central to family planning decisionmaking and yet readily admitted their failure to include men in family planning education and services. As one physician stated, "We tell the promoters that family planning counseling has to include both partners, but unfortunately the promoters only visit the women, because the men are at work." Another physician remarked, "You know that machismo dominates, but if we work with the couple, we can change some situations. For precisely that reason it is necessary to change the framework of family planning programs, which are oriented toward women only. This strategy does not work well, because it is the man who makes the ultimate decision."

Rather than analyzing how to involve men and provide them with family planning information, however, providers tended to identify them as major barriers to family planning practice. Some promoters hypothesized that men do not seek their services because they are not interested in contraception or oppose it because they are concerned about methods' side effects to health and fear losing control over their wives. Providers also highlighted some men's habitual drinking as an obstacle to consistent contraceptive use. Others said that they rarely interact with men and therefore could say little about their attitudes toward family planning. Commonly, providers overcome the obstacle of men's objection to family planning by supplying women with Depo Provera, a method that circumvents male involvement in contraceptive decisions.

By contrast, some providers described occasions of male involvement in family planning. Promoters from the Asociación Demográfica Salvadoreña (ADS) (the national affiliate of the International Planned Parenthood Federation), who live in the same communities as their clients, reported contact with men, particularly younger men who purchase condoms from them. Similarly, traditional birth attendants (TBAs), who play a vital role in the life of the community, report that men respect and interact frequently with them (FUSAL 2000). As one nurse explained, "In my experience, men as well as women trust the TBAs more than the promoters. I have seen [the TBAs] scold men for keeping their wives pregnant all the time, while on the other hand, the promoters never see the men because of their work hours." The TBAs stated that both women and men ask them about family planning, and that men sometimes express concern about the health risks of family planning or the influence it might have on their wives' fidelity.

\section{Program Implementation}

The project was implemented in 13 rural villages in five departments: Chalatenango, San Miguel, San Salvador, San Vicente, and Usulután. The villages were selected in coordination with the Ministry of Health according to three criteria: presence of a water and sanitation project, existence of an organized community association, and evidence of unmet need for family planning. The rural villages selected for the study are among the least developed in the country, which is why they were chosen by PCI to participate in water and sanitation projects. According to a national survey, roughly half of all women living in rural communities in El Salvador had three years or less of education. The fertility rate of women living in rural areas was 3.8 children per woman, almost double that of women living in urban areas (ADS et al. 2004). Most men in the study villages were agricultural workers or day laborers. Family income was often supplemented by remittances from relatives working in the United States. These characteristics are typical of many remote rural villages in El Salvador lacking domestic potable water. They reflect the conditions of about 60 percent of rural homes in the country. The distances between the intervention communities and the capital, San Salvador, range from 20 to 111 kilometers (about 13 to 70 miles), or about 20 minutes to an hour and a half by public transportation, depending on accessibility. Village populations ranged from approximately 100 to 2,000, with an average of 800 people per community.

The first steps in implementing the "Planning Together" program were to meet with the water boards, explain the project, and obtain the approval of commu- 
nity leaders. Next, PCI staff and existing water and sanitation volunteers were trained to incorporate family planning information into their educational activities. Group talks were presented to community members by PCI staff and the volunteers who motivated community members to participate. Water and sanitation volunteers referred couples interested in obtaining a family planning method to volunteers who had been trained by PCI to provide family planning counseling or to Ministry of Health services.

Family planning topics were integrated into ongoing educational activities conducted during the process of community mobilization and construction of water systems and latrines. The key themes in the family planning messages included in the water and sanitation education program were: the relationship between the protection of natural resources and the protection of family health through birth spacing; gender equity in making decisions about family and community resources; and the availability of a range of family planning methods to meet the particular needs of each couple. Simple drawings and trigger questions were used to stimulate discussion and transmit key messages. The messages were designed to help the community members understand the connection between the planning and protection of the family and the protection of natural resources. The objective was not to transform the water and sanitation project into a reproductive health project, but to awaken the interest of couples and motivate them to seek further information and services from family planning providers, including the $\mathrm{MOH}$, Asociación Demográfica Salvadoreña, and community volunteers providing the Standard Days Method.

The intervention consisted of two home visits. The first visit focused on the relationship between protecting natural resources and protecting the family's health and on the benefits of family planning and making decisions as a couple. The second home visit took place about a week later and covered in more detail fertility awareness, the menstrual cycle, family planning methods (including the Standard Days Method), and how to choose a family planning method. Volunteers referred couples interested in using a method to a provider. Group talks covered the same topics, using similar visual aids, but also included games and participatory activities. Research results were taken into account so that the intervention was designed to stimulate reflection on the influence of gender, sexuality, violence, and alcohol on contraceptive use. For example, volunteers encouraged reflection on gender inequity by showing a drawing of a man forbidding his wife to attend a community meeting. The volunteers followed up with such ques- tions as: "What is happening in this picture?" "How does the man feel?" "The woman?" "How could this situation be improved?" "When was the last time you and your partner made an important decision together?"

The presentation of family planning methods included explicit discussion of the ways that gender and sexuality-related factors, such as the risk of sexually transmitted infections, influence selection and use of a family planning method. Instructors explaining the Standard Days Method were trained to use a pictorial job aid to screen couples interested in using the SDM to determine whether the method was appropriate for them. For example, the job aid would help providers to identify couples with risk of sexually transmitted infections, domestic violence, or alcohol problems and other couple-related issues that could influence use of a contraceptive method. Instructors were also trained to address these couplerelated issues while teaching couples to use a method and while conducting follow-up visits.

Training of PCI staff and community volunteers was accomplished in several stages. At the beginning of the project, the $\mathrm{MOH}$ provided PCI facilitators with two days of family planning training (including role-playing and case studies) and an additional day of training in the Standard Days Method. PCI facilitators trained 110 water and sanitation volunteers to incorporate family planning topics into their activities, using the manual Planning Together (PROCOSAL et al. 2000). Once the educational activities were underway, staff from PCI and the Institute for Reproductive Health trained a smaller group of 24 community volunteers to serve as "instructors," providing condoms and the Standard Days Method and referring potential users of other methods to ADS and the $\mathrm{MOH}$. Bimonthly supervisory visits and a group refresher training three months later reinforced the initial training.

Training of staff and volunteers covered basic counseling principles, informed choice, contraceptive technology, criteria for method eligibility, and how to refer couples for family planning services. Instructors were also trained to screen and counsel couples interested in using the Standard Days Method or condoms. Both groups were given information on how to reach men. For example, they were advised of the need to conduct meetings in the evenings and weekends, when men are available, and were instructed on how to encourage both partners to express themselves during couples' counseling sessions. Staff and volunteers also learned how to teach women to discuss with their husbands family planning and protection against sexually transmitted infections. Because instructors would be providing methods dependent on couples' communication, they were also trained to discuss issues couples might have that are related to 
contraceptive use and sexuality and to address men's concerns about family planning.

The effort to reach men required institutional flexibility and innovation. PCI provided compensatory time and per diem compensation for staff to conduct meetings during evenings and weekends with men in rural areas. Volunteers went out into the fields to talk with men while they were working and also conducted home visits. For monitoring purposes, sex-specific indicators (such as the percentage of home visits conducted with men present) were incorporated into supervisory tools and activities. As one volunteer stated, "First we speak with the woman alone. Later we talk with both of them. That way the wife has already discussed [family planning] with her husband, so we can go there with confidence ... because it is not a surprise and they're both waiting for us." Staff and volunteers went to great lengths to reach couples and men, an effort that was more timeconsuming than talking with women alone.

The program relied on staff and volunteers to create a favorable environment for family planning through formal activities-home visits and group talks-and informal discussions with friends, neighbors, and relatives. Community-development boards also discussed family planning during their regular meetings and activities. In light of the high levels of community involvement and the program's focus on family planning and sexuality-topics of interest to community members-PCI anticipated that information would spread widely by word of mouth and expected that individuals would hear about the program, if not directly, through home visits or talks, then indirectly, through instructors, volunteers, community leaders, and participants. In fact, according to the follow-up survey, 73 percent of the respondents were aware that PCI had integrated family planning into its water and sanitation activities, and virtually all respondents approved of the initiative.

The communities were in different phases of implementation of their water and sanitation projects when PCI began its family planning initiative. In six of the communities, the "Planning Together" intervention and the water and sanitation project were introduced simultaneously. In the other seven communities, the family planning intervention was incorporated later in the process. This uneven scheduling made the work of the facilitators much more difficult because they had to plan special visits to these seven communities to work on the family planning component. PCI also found men and women in these seven communities less willing to participate in family planning activities. In the communities where the two components were introduced together, family planning topics were incorporated efficiently into discussions of rational use of resources, volunteer training, and outreach activities. In these villages, PCI staff and community members viewed the intervention as a truly integrated effort. PCI observed greater participation in the family planning activities in these communities, especially among men, because they were already mobilized to construct the water system.

\section{Project Evaluation}

This study addresses two issues: (1) the feasibility of integrating family planning education into water and sanitation programs, and (2) changes in knowledge, attitudes, and practices related to family planning over the course of the intervention. Indicators for assessing the first issue include: the proportion of the community covered by the intervention, the proportion of men reached by project activities, the acceptability of the intervention, and community members' awareness of PCI as a source of family planning information. Indicators for the second issue include: knowledge of family planning methods, including the Standard Days Method; attitudes toward men's involvement in family planning activities; communication between spouses; men's involvement in family planning decisionmaking; and use of contraceptives that involve male participation.

\section{Data Collection and Methodology}

A community-based household survey was conducted at the start and end of the project. The survey used a cluster sample of individuals of reproductive age as participants. Sample size was determined based on statistical calculations to ascertain the probability of detecting a 10-15 percent change in family planning knowledge and use between the baseline and endline surveys. At the baseline, conducted in January 2001, a total of 341 interviews (of 151 men and 190 women) were conducted. At the follow-up, conducted in September 2002, 364 individuals were interviewed (189 women and 175 men). Although the great majority of participants were either married or in union, the study was designed to interview one member of each couple sampled at baseline and endline. No attempt was made to interview the same respondents; both baseline and endline surveys represented independent samples. At the follow-up, men were oversampled to ensure that sufficient data were collected from men. Baseline and endline surveys included questions about sociodemographic characteristics, knowledge of reproductive health and family planning, previous 
and current use of contraceptives, family planning services, couples' decisionmaking and communication, attitudes, and community participation. The endline survey also included questions about the intervention and perceptions of the role of $\mathrm{PCI}$ as an organization that provides information about family planning. ${ }^{2}$

Data analysis was conducted using the SPSS statistical software. Initial bivariate analysis examined differences between knowledge, attitudes, and behaviors related to family planning before and after the intervention. Separate analyses are presented for men and women. Similar analyses of the postintervention data are provided, but comparisons also are made between respondents who were exposed to the intervention (at a community talk or during a home visit) and those who were not. Subsequent analysis uses logistic regression, with dichotomous outcome variables based on the respondents' knowledge, attitudes, and behaviors. All regressions include controls for age, education, and sex, because these factors could influence responses. Comparisons of baseline and postintervention data also control for when the participant was interviewed. Regressions that examine only the postintervention data include a control for whether the respondent had been exposed to the intervention. Regression coefficients are exponentiated and interpreted as odds ratios.

\section{Results}

Results are presented in two sections. The first considers the feasibility of providing family planning information within water and sanitation programs. The second examines changes in respondents' knowledge, attitudes, and behavior.

\section{Feasibility of Providing Family Planning Through Water Programs}

The follow-up survey provides information on the proportion of men and women in the community who were reached by project activities. Among the 364 community members interviewed in the endline survey, 49 percent reported having participated in the intervention. According to endline survey results, 46 percent of men and 51 percent of women participated in a home visit, group talk, or both. Thirty-eight percent of respondents participated in a group talk (36 percent of men and 40 percent of women). A smaller proportion (23 percent) of respondents reported having received a home visit from a volunteer (24 percent of men and 33 percent of women). Although volunteers tried to conduct the home visits with both part- ners, only 18 percent of the respondents reported that their partner was present during the home visit. Approximately 18 percent of those interviewed reported that they had participated in both the group talk and home visits.

Despite initial concerns expressed by PCI staff and community leaders, the expansion of $\mathrm{PCI}^{\prime}$ s role proved acceptable to the community. As a PCI outreach worker described the process:

At first, when they gave us this work, we were very concerned because after specializing in water and latrines, people are going to ask, "Why are these people talking about family planning?" But in the group talks they came to understand the relationship between resources and how everything was related. It worked very well, and people have had a lot of trust in us.

Most of the men and women interviewed (92 percent) stated that the integration of family planning into the water and sanitation program was both beneficial and necessary. Encouraging men to become involved in health matters fit well with the water projects. The local water committees and Ministry of Health personnel were pleased with the result of the project, and publicand private-sector organizations have expressed interest in replicating the model.

As a result of this initiative, $\mathrm{PCI}$ is now recognized as an organization that provides family planning information. Twenty-two percent of the men and women interviewed at the end of the study mentioned $\mathrm{PCI}$ as a source of family planning information. Indeed, PCI was cited in the community as the second most important source of family planning information, after the health center.

Similarly, the presence of PCI in these communities appears to have facilitated more frequent discussion of family planning, even among community members who did not participate in intervention activities. As one health volunteer commented:

Many people in our community have heard of family planning, but not very many are practicing it. People who are using a method don't tell anybody. During this project, we have taught people that they can discuss family planning freely, without being embarrassed.

Among women in the community, discussion of the subject during the three months prior to the survey increased from 12 percent to 22 percent; among men, the levels increased from 13 percent to 18 percent. The family planning topics most frequently discussed among community members were the advantages of contraception (24 percent), the Standard Days Method (22 percent), 
and other contraceptive methods (33 percent). This level of conversation in the community suggests the importance of informal networks for diffusing information about family planning. No other group was working with the Standard Days Method at the time of the study, so the frequency of conversation about the method illustrates the importance of informal networks in disseminating information.

Another indicator of the informal diffusion of information is that during the follow-up survey, 14 women were identified who had been taught to use the Standard Days Method by a friend, relative, or untrained physician or nurse. These women were using photocopied CycleBeads and calendars or had used versions distributed to providers in informational meetings. As one focus-group participant commented:

My sister-in-law already has six children, and she doesn't want any more. I showed her the method and I drew pictures of the necklace for her on various pages. She marks them with a sign like a ring.

At the end of the project, health promoters from the $\mathrm{MOH}$ mentioned that they had observed changes in the way family planning information spread through the community. They reported that as a result of the work of the volunteers, family planning is no longer a taboo topic among some groups, especially among men, and is discussed regularly in community meetings of all types. For example, one health promoter stated that he could address the topic of family planning more easily because families had received information about "Planning Together," which provided a context for the discussion. Health promoters stated that PCI's strategy had reduced the taboo of discussing family planning with men, and they saw more willingness among men to attend talks on the subject. Moreover, the project's ideas were spread by means of the water boards to other communities. Framing the discourse in terms of a couple "planning together" demystified family planning and facilitated its introduction into meetings and events concerning subjects other than health. Community volunteers mentioned that the topic of family planning is more acceptable when phrased in terms of couples' communication and that previously men felt left out of programs. They had been unable to find a way to be involved without feeling that they were "losing their manhood."

The recognition of the commonalities between community resources, natural resources, and family resources motivated the water boards to continue to discuss family planning topics during their meetings and to include family planning education in their sustainability plans, even after PCI phased out activities in proj- ect communities. During end-of-study meetings, researchers found that some water boards had included family planning meetings in their future work plans, with the justification that if families grew too quickly, the latrines and water system they had worked so hard to build would soon become insufficient to meet the community's needs.

\section{Changes in Knowledge, Attitudes, and Behavior}

Over the course of the intervention, significant changes in knowledge, attitudes, and behavior related to family planning took place. Regression results are presented below for sets of variables that describe respondents' knowledge, level of discussion with spouses, and attitudes. Decisionmaking regarding the selection of a family planning method and whether the decision was made by the woman, the man, or together, is discussed.

\section{Descriptive Analyses}

Data for respondents' characteristics are similar for the baseline and endline surveys (see Table 2). Mean age and educational distribution among women interviewed before and after the program intervention are not appreciably different. Comparing the educational distribution among men also reveals no significant difference, although male survey participants at endline were significantly older than baseline participants (31.6 versus 36.3 years).

\section{Contraceptive Knowledge}

Both men and women interviewed at endline demonstrated greater awareness of the injectable contraceptive and the condom than those at baseline. Men reported a significant increase in the proportion who understood that men are always fertile. (Respondents did not know about the Standard Days Method in the baseline survey, so these differences in means are measurable only between participants and nonparticipants in the intervention.)

Women who received some part of the intervention were more knowledgeable about which days during the menstrual cycle they are fertile than were those who did not participate in the intervention. Intervention participants also reported significantly higher levels of awareness of the Standard Days Method (45 percent as compared with 8 percent) and of how to use the method ( 28 percent as compared with 3 percent). These women also were more aware of condoms than were women who did not participate in the intervention (40 percent versus 23 percent). Participating men reported significantly higher levels of knowledge related to male fertility and to the three family planning methods included in the sur- 
Table 2 Percentage of respondents reporting knowledge, attitudes, and behavior, according to sex, program participation, and baseline/endline, EI Salvador, 2001-02

\begin{tabular}{|c|c|c|c|c|c|c|c|c|}
\hline \multirow[b]{3}{*}{ Variable } & \multicolumn{4}{|c|}{ Women } & \multicolumn{4}{|c|}{ Men } \\
\hline & \multirow{2}{*}{$\begin{array}{c}\text { Baseline } \\
\text { Total }\end{array}$} & \multicolumn{3}{|c|}{ Follow-up } & \multirow{2}{*}{$\begin{array}{c}\text { Baseline } \\
\text { Total }\end{array}$} & \multicolumn{3}{|c|}{ Follow-up } \\
\hline & & Total & $\begin{array}{l}\text { Program non- } \\
\text { participants }\end{array}$ & $\begin{array}{c}\text { Program } \\
\text { participants }\end{array}$ & & Total & $\begin{array}{l}\text { Program non- } \\
\text { participants }\end{array}$ & $\begin{array}{c}\text { Program } \\
\text { participants }\end{array}$ \\
\hline \multicolumn{9}{|l|}{ Respondents' characteristics } \\
\hline Age (mean) & 30.3 & 30.4 & 29.6 & 31.2 & 31.6 & $36.3^{\star \star *}$ & 34.3 & $38.6^{\star \star \star}$ \\
\hline$\leq 29$ years & 48.9 & 48.7 & 52.2 & 45.4 & 42.4 & $30.3^{\star \star}$ & 37.9 & 21.3 \\
\hline 30-39 years & 36.8 & 32.8 & 32.6 & 33.0 & 35.8 & 30.9 & 28.4 & 33.8 \\
\hline$\geq 40$ years & 14.2 & 18.5 & 15.2 & 21.6 & 21.9 & 38.9 & 33.7 & 45.0 \\
\hline \multicolumn{9}{|l|}{ Education } \\
\hline None & 17 & 19 & 19 & 19 & 13 & 15 & 17 & 13 \\
\hline Primary incomplete & 56 & 46 & 41 & 50 & 42 & 39 & 35 & 44 \\
\hline Primary complete+ & 27 & 36 & 40 & 32 & 44 & 46 & 48 & 44 \\
\hline \multicolumn{9}{|l|}{ Contraceptive knowledge } \\
\hline Men are always fertile & 47 & 54 & 47 & 60 & 54 & $72^{\star \star \star}$ & 65 & $80^{\star}$ \\
\hline Women's fertile times & 6 & 7 & 2 & $12^{\star *}$ & 5 & 9 & 8 & 10 \\
\hline Awareness of pill & 71 & 76 & 73 & 78 & 56 & 63 & 57 & 70 \\
\hline Awareness of injectables & 58 & $74^{\star \star \star}$ & 78 & 69 & 35 & $57^{\star \star \star}$ & 50 & $65^{\star}$ \\
\hline Awareness of Standard Days Method & - & 27 & 8 & $45^{\star \star \star}$ & - & 18 & 7 & $30^{* \star *}$ \\
\hline Use of Standard Days Method & - & 16 & 3 & $28^{\star * *}$ & - & 11 & 2 & $23^{\star \star \star}$ \\
\hline Awareness of IUD & 20 & 28 & 28 & 28 & 7 & 11 & 6 & $18^{\star}$ \\
\hline Awareness of condom & 23 & $32^{*}$ & 23 & $40^{\star *}$ & 56 & $71^{* *}$ & 71 & 71 \\
\hline \multicolumn{9}{|l|}{ Family planning attitudes } \\
\hline Natural method not effective & 60 & $40^{\star \star *}$ & 40 & 40 & 56 & $39^{* *}$ & 32 & $49^{*}$ \\
\hline Men will not use natural methods & 58 & $41^{* \star *}$ & 44 & 38 & 44 & $29^{\star *}$ & 30 & 29 \\
\hline Men decide the number of children to have & 32 & 38 & 40 & 35 & 42 & 35 & 37 & 34 \\
\hline Women who use contraceptives are unfaithful & 26 & 25 & 28 & 23 & 33 & 37 & 38 & 35 \\
\hline Men with more children are more masculine & 15 & 20 & 21 & 19 & 11 & 11 & 15 & 8 \\
\hline $\begin{array}{l}\text { Men should not participate in family } \\
\text { health matters }\end{array}$ & 60 & $21^{\star \star \star}$ & 22 & 21 & 60 & $11^{* \star *}$ & 12 & 10 \\
\hline $\begin{array}{l}\text { Women have last say regarding contra- } \\
\text { ceptive method used }\end{array}$ & 59 & 67 & 62 & 71 & 48 & 57 & 60 & 53 \\
\hline \multicolumn{9}{|l|}{ Behavior } \\
\hline \multicolumn{9}{|l|}{ Discussed in previous six months } \\
\hline Number of children & 28 & $53^{\star \star *}$ & 50 & 57 & 38 & 47 & 44 & 51 \\
\hline Using family planning method & 22 & $36^{\star *}$ & 36 & 36 & 20 & $37^{\star *}$ & 32 & 36 \\
\hline Which family planning method to use & 23 & $37^{\star \star}$ & 35 & 39 & 20 & $34^{\star *}$ & 32 & 36 \\
\hline Man's role in family planning & 7 & $16^{\star *}$ & 15 & 17 & 5 & $23^{\star \star \star}$ & 18 & 29 \\
\hline Woman's fertile times & 11 & $23^{\star \star \star}$ & 21 & 26 & 13 & $29^{\star \star \star}$ & 24 & 34 \\
\hline Risk of sexually transmitted infections & 20 & $35^{\star \star *}$ & 26 & $43^{*}$ & 24 & $47^{\star \star \star}$ & 43 & 53 \\
\hline \multicolumn{9}{|l|}{ Contraceptive use } \\
\hline Use of any method & 45 & 52 & 48 & 57 & 44 & $63^{\star * \star}$ & 62 & 65 \\
\hline Use of couple-based method & 29 & 22 & 23 & 22 & 33 & 39 & 44 & 33 \\
\hline$(\mathrm{N})$ & $(190)$ & $(189)$ & (92) & $(97)$ & $(151)$ & $(175)$ & (95) & $(80)$ \\
\hline
\end{tabular}

${ }^{*}$ Significant at $\mathrm{p} \leq 0.05 ;{ }^{* \star} \mathrm{p} \leq 0.01 ;{ }^{* \star \star} \mathrm{p} \leq 0.001 . \quad-=$ Not applicable.

vey questions than did those who did not participate. Male participants at endline were more aware than nonparticipants that men are always fertile ( 80 percent as compared with 65 percent). Similarly, male participants were significantly more knowledgeable than nonparticipants about the Standard Days Method-with respect to both awareness of the method (30 percent and 7 percent) and knowledge of how to use the method (23 percent and 2 percent).

\section{Family Planning Attitudes}

The differences in attitudes between community members at baseline and follow-up were, surprisingly, more significant than the differences in attitudes between those who did versus those who did not participate in the intervention. For example, a dramatic decline is seen from baseline to follow-up in the proportion of female and male respondents agreeing with the statement that men should not participate in family health matters (from 60 to 21 percent and from 60 to 11 percent, respectively), but almost no difference in this attitude is found between program participants and nonparticipants. A similar shift occurred among people who at baseline expressed the attitude that men will not use natural methods (a decline from baseline to follow-up of 58 to 41 percent for women and 44 to 29 percent for men). 
One perplexing finding was the greater proportion of male participants than male nonparticipants who believed that natural methods were not effective (49 versus 32 percent). One possible explanation for this result is that PCI facilitators and volunteers discussed the full range of family planning methods during the community talks. PCI likely described the calendar rhythm method, commonly practiced in the study villages, as an ineffective form of family planning. Thus, the men who were participants learned that rhythm and withdrawal, which they considered to be natural methods, are not effective, whereas men who were not participants may have learned through diffusion of information that the Standard Days Method is a new, effective natural method, but did not learn that rhythm and withdrawal are not effective. The nonparticipants may have concluded that because the SDM is available, natural methods are effective.

\section{Behavior}

A noteworthy finding of this study is that reported discussion of various topics related to family planning between partners increased during the intervention period not only among program participants but throughout the community. Men in the community reported that discussion of the man's role in family planning quadrupled from 5 to 23 percent, whereas women reported that it doubled from 7 to 16 percent; both are statistically significant increases. The likelihood of discussing the possibility of practicing family planning, which method to use, women's fertile times, and the risk of sexually transmitted infections likewise increased significantly for both sexes. When considering the differences between participants and nonparticipants at the follow-up survey, only one of the 12 indicators (women reporting discussion of STI risk) was significantly different from baseline ( 43 percent versus 26 percent). This finding suggests that the intervention may have succeeded in catalyzing a community-level discussion that spread beyond intervention participants.

Overall contraceptive prevalence increased significantly over the course of the study from 45 percent to 58 percent (not shown). Results presented in Tables 3 and 4 break down these prevalence figures by sex and intervention status. Men's reported use of any contraceptive method was significantly higher at the endline than at the baseline (63 percent as compared with 44 percent). Other results were not significant. Similarly, for the proportion of respondents who reported using a method that required male involvement or agreement, none of the findings was significant.
Table 3 Odds ratios for community members who reported family planning knowledge, attitudes, and behavior, by age, education, sex, and survey, El Salvador, 2001-02

\begin{tabular}{|c|c|c|c|c|c|}
\hline \multirow[b]{2}{*}{ Indicator } & \multicolumn{2}{|c|}{ Age } & \multirow[b]{2}{*}{$\begin{array}{l}\text { Edu- } \\
\text { cation }\end{array}$} & \multirow[b]{2}{*}{ Sex } & \multirow[b]{2}{*}{$\begin{array}{r}\text { Survey } \\
\text { time }\end{array}$} \\
\hline & $<30$ & $40+$ & & & \\
\hline \multicolumn{6}{|l|}{ Contraceptive knowledge } \\
\hline Men are always fertile & $0.60^{\star \star}$ & 1.02 & 1.07 & $1.58^{\star \star}$ & $1.55^{\star \star}$ \\
\hline Women's fertile times & 0.54 & 0.71 & $1.92^{* *}$ & 0.94 & 1.58 \\
\hline Awareness of pill & 0.74 & $0.56^{\star \star}$ & $1.76^{\star}$ & $0.50^{\star \star \star}$ & 1.34 \\
\hline Awareness of injectables & 0.90 & $0.49^{\star * \star}$ & * $1.66^{\star *}$ & $0.43^{\star * *}$ & $2.36^{\star \star \star}$ \\
\hline Awareness of IUD & $0.62^{*}$ & 1.22 & 1.33 & $0.27^{\star \star \star}$ & $1.56^{*}$ \\
\hline Awareness of condom & 0.91 & 0.86 & $1.66^{\star \star}$ & $4.65^{\star \star \star}$ & $1.72^{\star \star \star}$ \\
\hline \multicolumn{6}{|l|}{ Family planning attitudes } \\
\hline Natural method not effective & 1.12 & 0.90 & 1.15 & 0.92 & $0.49^{\star \star \star}$ \\
\hline Men will not use natural methods & 0.90 & 1.03 & $0.95^{\star *}$ & $0.58^{\star * *}$ & $0.50^{\star \star *}$ \\
\hline $\begin{array}{l}\text { Men decide the number of } \\
\text { children to have }\end{array}$ & 1.01 & 1.07 & $0.51^{*}$ & 1.29 & 1.02 \\
\hline $\begin{array}{l}\text { Women who use contraceptives } \\
\text { are unfaithful }\end{array}$ & 1.00 & 1.47 & 0.76 & $1.51^{*}$ & 1.06 \\
\hline $\begin{array}{l}\text { Men with more children are } \\
\text { more masculine }\end{array}$ & 1.31 & 0.98 & $0.51^{\star *}$ & 0.69 & 1.32 \\
\hline $\begin{array}{l}\text { Men should not participate in } \\
\text { family health matters }\end{array}$ & 1.18 & $1.63^{\star}$ & 0.87 & 0.73 & $0.13^{\star \star \star}$ \\
\hline $\begin{array}{l}\text { Women have last say regarding } \\
\text { contraceptive method used }\end{array}$ & 0.99 & 1.04 & 1.34 & $0.61^{\star \star}$ & $1.38^{*}$ \\
\hline \multicolumn{6}{|l|}{ Behavior } \\
\hline \multicolumn{6}{|l|}{ Discussed in previous six months } \\
\hline Number of children & 1.30 & $0.63^{\star}$ & 1.20 & 1.17 & $2.26^{\star \star \star}$ \\
\hline $\begin{array}{l}\text { Using family planning method } \\
\text { Which family planning }\end{array}$ & $1.49^{*}$ & $0.61^{*}$ & 1.05 & 1.00 & $2.18^{\star \star *}$ \\
\hline method to use & $1.47^{*}$ & 0.63 & 1.26 & 0.92 & $2.13^{\star \star \star}$ \\
\hline Man's role in family planning & 0.81 & 0.77 & 1.27 & 1.25 & $3.45^{\star \star \star}$ \\
\hline Woman's fertile times & 0.86 & 0.73 & 1.32 & 1.25 & $2.64^{\star \star \star}$ \\
\hline $\begin{array}{l}\text { Risk of sexually transmitted } \\
\text { infections }\end{array}$ & 0.70 & 0.65 & 1.17 & $1.52^{*}$ & $2.59^{\star \star \star}$ \\
\hline \multicolumn{6}{|l|}{ Contraceptive use } \\
\hline Use of any method & 0.85 & 0.93 & 1.06 & 1.23 & $1.68^{\star \star \star}$ \\
\hline Use of couple-based method & 1.19 & 0.54 & 1.08 & $1.91^{* *}$ & 1.01 \\
\hline $\begin{array}{l}\text { *Difference significant at } \mathrm{p} \leq 0.05 ; \\
\text { variable with reference group age } \\
\text { ence group age } 30-39 \text {. Educat } \\
\text { plete+; } 0=<\text { primary. Sex: Dichot } \\
\text { vey: Dichotomous variable: } 1=\text { en } \\
\text { method: Dichotomous variable: amc } \\
1=\text { using a method involving male } \\
\text { male methods. }\end{array}$ & $\begin{array}{l}\text { ion: Dich } \\
\text { dline; } 0=\end{array}$ & $\begin{array}{l}\text { ariable: } 1 \\
\text { = baselin } \\
\text { ndents i }\end{array}$ & $\begin{array}{l}.001 . \\
\text { Dummy } \\
\text { s variable } \\
1 \text { = man; } \\
\text { ne. Us } \\
\text { indicating } \\
\text { ment or } p\end{array}$ & $\begin{array}{l}\text { Age }<30 \\
\text { ariable } \mathrm{n} \\
1=\text { prim } \\
=\text { woma } \\
\text { of coup } \\
\text { se of any } \\
\text { rticipatio }\end{array}$ & $\begin{array}{l}\text { D: Dummy } \\
\text { with refer- } \\
\text { nary com- } \\
\text { an. Sur- } \\
\text { ple-based } \\
\text { ly method, } \\
\text { on; } 0=\text { fe- }\end{array}$ \\
\hline
\end{tabular}

\section{Regression Results: Baseline Versus Endline Surveys}

Table 3 presents regression results comparing changes between the baseline and endline surveys. Regressions include controls for age, education, sex, and when the interview was conducted (baseline and endline). Results are presented as odds ratios of the effect of the independent variable on each of the dependent variables.

\section{Contraceptive Knowledge}

Overall, the most significant factors affecting knowledge were sex, effect of intervention period (from baseline to endline), and education. The effects of age on knowledge tended to be far less significant and consistent. Being male was a significant predictor of five of the six knowl- 
edge variables. Although the effects were not consistent, they follow a pattern showing that men and women have greater knowledge of matters relevant to their own sex. Men were significantly more likely than women to be aware that men are always fertile. The most significant finding among the contraceptive knowledge variables concerns condoms: men were four times more likely than women to know about condoms. Women were significantly more likely than men, however, to be aware of the pill, injectables, and the intrauterine device (IUD) all female methods. The time at which the data were collected also affected knowledge. Respondents were significantly more likely to know that men are always fertile at endline than they were at the time of baseline survey. Similarly, knowledge of injectables, the IUD, and the condom was also higher at endline than at baseline. Finally, education had significant effects on the contraceptive knowledge variables. Respondents with higher levels of education were more likely to be aware of when women are fertile during their cycle. Higher education also predicted greater knowledge of the pill, injectables, and the condom.

\section{Family Planning Attitudes}

Results of the regressions on attitudes show relatively few significant findings. The limited number of attitudinal measures showing significant change may be a reflection of the short time over which the intervention was implemented or may indicate that the intervention was designed to involve men in family planning and not to change deeply rooted cultural attitudes and beliefs. Three covariates yielded significant and interesting effects: time, sex, and education.

At endline, respondents were significantly less likely to believe that men are unwilling to use natural methods and less likely to consider natural methods ineffective (for reasons described above). Perhaps the most significant finding in the regressions had to do with whether or not men should be involved in family health. At endline, respondents were 0.13 times less likely to indicate that men should not participate in family health than they were at baseline. Alternatively stated, at baseline the odds of a participant's agreeing with the statement were nearly eight times greater than at endline. The size, direction, and significance of this result indicate that the "Planning Together" intervention had a noteworthy effect on the perceived role of men in family health. Participants were also more likely at endline to believe that women should have the last say in deciding which method of family planning to use.

Three attitudes were significantly affected by the sex of respondents. Two of these-that men will not use natural methods of family planning and that women should have the last say in deciding which family planning method to use-were significantly more frequently expressed by women. The first finding reflects either that women underestimate men's support of natural methods or that men overstate their support. Men, by contrast, were significantly more likely to believe that women who use contraceptives are unfaithful. This and other culturally based attitudes are difficult to change, especially by means of a short-term intervention.

Education was also a significant predictor of two of the culturally ingrained attitudes. Participants with low levels of education were more likely than others to respond that men should decide the number of children that a woman should have, and also that the more children a man has, the more masculine he is.

\section{Behavior}

By far, the most significant findings concerning behavior were related to changes in partners' communication between the baseline and endline surveys. Participants were vastly more likely at endline to report having discussed topics related to family planning and STI risk in the previous six months than they were at baseline. Other interesting findings were that participants younger than 30 were more likely to have talked with their partners about family planning issues than were older respondents and that men were more likely than women to report discussing STI risk with their partners.

Regarding contraceptive use, the only significant result related to the time of data collection. The odds of respondents' reporting that they were using a family planning method were 1.68 times greater at endline than at baseline. Concerning the odds of respondents' reporting use of methods that require men's agreement or participation, however, the only significant variable was sex: men reported 1.91 greater incidence of use of methods requiring men's involvement than was reported by women.

\section{Regression Results: Participants Versus Nonparticipants}

The second set of regression results, shown in Table 4, is restricted to the responses of intervention participants interviewed for the endline survey, and comparisons are made with the responses of nonparticipants.

\section{Contraceptive Knowledge}

As with the results shown in Table 3, education, sex, and exposure to the intervention each affected knowledge significantly. Participants with more education were 
Table 4 Odds ratios for intervention participants at follow-up who reported family planning knowledge, attitudes, and behavior, by age, education, sex, and comparison to nonparticipants, El Salvador, 2002

\begin{tabular}{|c|c|c|c|c|c|}
\hline \multirow[b]{2}{*}{ Indicator } & \multicolumn{2}{|c|}{ Age } & \multirow{2}{*}{$\begin{array}{l}\text { Edu- } \\
\text { cation }\end{array}$} & \multirow[b]{2}{*}{ Sex } & \multirow{2}{*}{$\begin{array}{l}\text { Inter- } \\
\text { vention }\end{array}$} \\
\hline & $<30$ & $40+$ & & & \\
\hline \multicolumn{6}{|l|}{ Contraceptive knowledge } \\
\hline Men are always fertile & $0.58^{\star}$ & 1.13 & 1.36 & $2.03^{\star *}$ & $1.85^{\star \star}$ \\
\hline Women's fertile times & 0.83 & 0.73 & 1.35 & 1.31 & $2.35^{\star}$ \\
\hline Awareness of pill & 0.85 & $0.54^{\star}$ & $1.74^{\star}$ & $0.57^{\star}$ & $1.70^{*}$ \\
\hline Awareness of injectables & 1.01 & $0.52^{\star}$ & $1.84^{\star}$ & $0.50^{\star *}$ & 1.26 \\
\hline Awareness of IUD & 0.93 & 1.90 & 1.07 & $0.28^{\star * \star}$ & 1.33 \\
\hline Awareness of condom & 0.96 & 0.65 & $2.18^{\star \star \star}$ & $5.91^{\star \star \star}$ & $1.73^{*}$ \\
\hline \multicolumn{6}{|l|}{ Awareness of Standard Days } \\
\hline Method & 0.79 & 0.80 & $1.95^{\star}$ & $0.55^{\star}$ & $8.24^{\star}$ \\
\hline Use of Standard Days Method & 0.67 & 0.76 & 1.89 & 0.66 & $12.87^{\star \star \star}$ \\
\hline \multicolumn{6}{|l|}{ Family planning attitudes } \\
\hline Natural method not effective & 1.30 & 0.89 & 1.21 & 1.04 & 1.49 \\
\hline Men will not use natural methods & 0.96 & 1.10 & 0.85 & $0.59^{*}$ & 0.85 \\
\hline $\begin{array}{l}\text { Men decide the number of } \\
\text { children to have }\end{array}$ & 0.88 & 1.27 & $0.52^{\star *}$ & 0.89 & 0.77 \\
\hline $\begin{array}{l}\text { Women who use contraceptives } \\
\text { are unfaithful }\end{array}$ & 1.01 & 1.43 & 0.87 & 1.58 & 0.78 \\
\hline $\begin{array}{l}\text { Men with more children are } \\
\text { more masculine }\end{array}$ & 1.35 & 1.34 & $0.51^{*}$ & 0.54 & 0.67 \\
\hline $\begin{array}{l}\text { Men should not participate in } \\
\text { family health matters }\end{array}$ & 1.36 & 1.47 & 0.66 & $0.46^{\star}$ & 0.88 \\
\hline $\begin{array}{l}\text { Women have last say regarding } \\
\text { contraceptive method used }\end{array}$ & 0.84 & 0.93 & 1.07 & $0.64^{\star}$ & 1.04 \\
\hline \multicolumn{6}{|l|}{ Behavior } \\
\hline \multicolumn{6}{|l|}{ Discussed in past six months } \\
\hline Number of children & 1.31 & 0.64 & 1.25 & 0.90 & 1.45 \\
\hline Using family planning method & 1.67 & 0.71 & 1.22 & 1.06 & 1.24 \\
\hline $\begin{array}{l}\text { Which family planning method } \\
\text { to use }\end{array}$ & 1.56 & 0.72 & 1.47 & 0.98 & 1.37 \\
\hline Man's role in family planning & 0.72 & 0.75 & 1.21 & 1.58 & 1.46 \\
\hline Women's fertile times & 0.81 & 0.68 & 1.41 & 1.35 & 1.53 \\
\hline $\begin{array}{l}\text { Risk of sexually transmitted } \\
\text { infections }\end{array}$ & $0.49^{\star \star}$ & $0.51^{*}$ & 1.29 & $1.75^{\star}$ & $1.78^{\star \star}$ \\
\hline \multicolumn{6}{|l|}{ Contraceptive use } \\
\hline Use of any method & 1.25 & 1.06 & 0.98 & $1.66^{*}$ & 1.31 \\
\hline Use of a couple-based method & 0.98 & 0.58 & 0.87 & $2.44^{\star \star *}$ & 0.75 \\
\hline \multicolumn{6}{|c|}{$\begin{array}{l}{ }^{*} \text { Difference significant at } \mathrm{p} \leq 0.05 ;{ }^{* *} \mathrm{p} \leq 0.01 ;{ }^{* *} \mathrm{p} \leq 0.001 \text {. Age }<30 \text { : Dummy } \\
\text { variable with reference group age } 30-39 \text {. Age } 40+\text { : Dummy variable with refer- } \\
\text { ence group age } 30-39 \text {. Education: Dichotomous variable: } 1=\text { primary com- } \\
\text { plete+; } 0=<\text { primary. Sex: Dichotomous variable: } 1=\text { man; } 0=\text { woman. In- } \\
\text { tervention: Dichotomous variable: } 1=\text { participated in talk, home visit, or both; } 0= \\
\text { did not report participating in any part of intervention. Use of couple-based } \\
\text { method: Dichotomous variable: among respondents indicating use of any method, } \\
1=\text { using a method involving male partner's agreement or participation; } 0=\text { fe- } \\
\text { male method. }\end{array}$} \\
\hline
\end{tabular}

more likely than those with less to be aware of the pill, injectables, condoms, and the Standard Days Method. The sex of respondents also affected several of the knowledge variables. Men were more likely than women to understand that they are always fertile and to be aware of condoms as a means of family planning. Women, on the other hand, were more likely than men to be aware of the pill, injectables, the IUD, and the Standard Days Method.
Respondents who participated in any form of intervention were significantly more likely than those who did not to understand that men are always fertile and that women are fertile only during certain days of the menstrual cycle. Similarly, they were more likely to be aware of the pill and condom as methods of family planning. Because the Standard Days Method was introduced as part of the intervention, it is not surprising that intervention participants were significantly more aware of the method and how to use it than were respondents who did not participate in the intervention.

\section{Family Planning Attitudes}

In contrast with results from attitudinal data for all community members at endline, few factors had a significant effect on attitudes expressed by intervention participants at endline. Neither participation in the intervention nor age affected any of the results concerning attitudes. Participants with lower levels of education were more likely to agree with the statement that men decide the number of children to have and that the more children a man has, the more masculine he is. Female participants were significantly more likely than male participants to state that men are unwilling to use natural methods of family planning, that men should not participate in family health matters, and that women should make the final decision as to which contraceptive method is used.

\section{Behavior}

Discussion among couples of STI risk was the only form of communicative behavior that was significantly predicted by any of the variables examined. Participants in their thirties were more likely than younger and older respondents to have discussed STI risk, men were more likely than women to have discussed it, and intervention participants were more likely than nonparticipants to have discussed this risk. Contraceptive use was more frequently reported by men than by women. Men were also significantly more likely than women to report that they and their partners were practicing some form of family planning and that they were using a couple-based method.

\section{Discussion and Conclusions}

Although substantial differences are found in the reported knowledge, attitudes, and behavior of community members before and after Project Concern International's family planning intervention, the differences between the people who participated in the intervention and those who did not are much smaller. This find- 
ing - that communitywide changes exceeded relative changes among individuals exposed to the intervention as compared with individuals who were not exposedsuggests the existence of a community effect. Such an effect would be consistent with Rogers's theory of the diffusion of innovations, defined as "the process by which an innovation is communicated through certain channels over time among the members of a social system ... [leading to] social change" (Rogers 1995). This theory has been particularly helpful in explaining how normative change comes about, precisely the kind of change that could encourage men to take a more active role in family planning.

According to the theory, individuals who are receptive to new ideas are influenced by the thinking and practices of leaders whom they respect, and they may in turn influence others. When a critical mass of these individuals adopt the ideas, the mainstream social group follows suit, resulting in a change in social norms. Evidence of this effect has been documented in research on other family planning programs (Murphy 2004). In our study setting, people began talking about the issues even when they themselves were not directly exposed to a group talk or home visit from a PCI facilitator or community volunteer. This is an expected consequence of the strategy of involving community development boards and training volunteers in order to stimulate discussion and provide information on topics related to family planning in community meetings. Volunteers did not restrict discussion of these issues to planned home visits; they also raised them during informal conversations with friends and relatives.

Another result of the program was that it brought about greater levels of communication between partners. Recent research suggests that poor communication, often related to gender norms and inequities, is a major obstacle to improving sexual and reproductive health (Paulson and Bailey 2003). Interventions of short duration are not likely to change deeply ingrained cultural norms. Some attitudinal changes were observed nonetheless, changes that appear to have expanded men's and women's ideas of the role men can play in family health matters. By improving couples' communication, programs can contribute to changing norms about sexual relationships and family planning.

Reaching men through traditional health networks is difficult. The results of this study suggest that promoting informal communication networks to increase knowledge and change attitudes can be an effective strategy for increasing male involvement in family planning. This study documents a significant increase in discussions of topics related to family health over the time of the inter- vention, even among people not directly exposed to the program. The success of this intervention in increasing discussion between spouses may have resulted from the way it was integrated into an already successful water and sanitation project equipped with its own outreach infrastructure for involving many men and women in the community. This experience suggests that incorporating family planning into community development projects that are unrelated to health services is feasible if sufficient commitment and resources exist, including the willingness to adapt policies and procedures (for example, making accommodations for staff to work evenings and weekends). Similar sorts of initiatives could be conducted with other projects that typically involve men, such as campaigns to control mosquito-borne disease.

For reaching men, community-based programs may have an advantage over vertically organized health services. Mobilizing male and female community leaders to provide family planning information is one strategy for overcoming the health system's difficulty in reaching men. Volunteer networks can provide information to their communities, finding opportunities to talk with men on the football field, at the corner store, or in farm fields. This effort requires, however, adequate training of and follow-up with volunteers to ensure that accurate information is spread.

From an organizational perspective, this project demonstrated that family planning can be integrated into water and sanitation projects. PCI staff and community members found the strategy acceptable; the organization reports that this initiative has enhanced its image. PCI is now viewed in El Salvador as a source of family planning information and services and intends to include the family planning component in all of their programs, working with other organizations.

Despite PCI's success, replicating these results elsewhere will require responsiveness to several factors that may impinge on a program's effectiveness. The integration of family planning was far more successful in communities where the water project and family planning education were initiated simultaneously than in those where the family planning component was added later. Another factor is cost. This type of initiative requires substantial costs in terms of staff time and resources. The added responsibilities of family planning activities sometimes were a burden for the overworked staff. The demands were greatest on the outreach workers because of their many responsibilities.

Although the study produced noteworthy findings concerning the increased involvement of men in family planning, study limitations should be mentioned. The cross-sectional design of the study does not allow for 
a strict comparison of variables for the same individual before and after the intervention. The two surveys provide snapshots only, and the differences in the two snapshots are attributed to the intervention. Such a study design might lead to overstating the effect of the "Planning Together" strategy, particularly if other family planning initiatives were underway simultaneously. Because no other such initiatives or complementary interventions were occurring in the study communities at the time of this intervention, however, we can reasonably attribute the changes observed to the influence of the PCI initiative. Although the study design could have been strengthened by interviewing the same individuals at baseline and endline, the two surveys use random sampling based on clusters, which is considered an acceptable design for assessing the effect of a communitybased intervention.

A common approach to introducing a programmatic focus on reproductive health topics is to incorporate such a focus into the ongoing work of health programs. This study, by contrast, demonstrates how, with a little creativity, these topics can be introduced into other sorts of programs as well. In this case of Project Concern International's family planning initiative in El Salvador, highlighting the relationship between protecting the environment and protecting family health and the relationship between gender equity in family planning decisionmaking and in community governance proved an effective means to catalyze public discussion of intimate issues related to power and sex.

An exciting consequence of this intervention study and other research conducted in El Salvador is that the Ministry of Health has included the Standard Days Method in its family planning program. The Standard Days Method was shown to be acceptable to the community, especially among those practicing contraception for the first time. Emphasizing instruction in the Standard Days Method was a useful strategy for increasing male involvement in family planning, and PCI ultimately trained $\mathrm{MOH}$ nurses and promoters in the method. Providers as well as community members clearly saw the imperative of including men in discussions that addressed male and female fertility and the methods used by men. As a result of this intervention, men's knowledge of matters related to family planning, such as fertility awareness and STIs-topics included in the introduction of the Standard Days Method-increased substantially, as did their involvement in discussions of related topics. Including a natural method in discussions of family planning also made the intervention acceptable to community groups that had previously opposed family planning initiatives.

\section{Notes}

1 Fertility-awareness-based methods of family planning depend on identifying the days when intercourse is most likely to result in a pregnancy. The Standard Days Method and the calendar rhythm method both involve counting the days in the menstrual cycle. Unlike the SDM, however, which requires only that the woman know which day of her menstrual cycle she is currently at and that she consider herself potentially fertile on days 8 through 19, the calendar rhythm method requires also that the woman have a record of the length of her last several menstrual cycles, identify the longest and shortest of these cycles, and perform a mathematical calculation to identify her days of probable fertility during the current cycle. Users of the Billings ovulation method, another wellknown fertility-awareness-based method, observe and chart their cervical secretions and apply rules to the observed patterns to identify their fertile days. The first-year probability of pregnancy for users of the Billings method is about 3 percent among those who use it perfectly. By contrast, the calendar rhythm method lacks consistent rules, and its efficacy has never been tested in a well-designed prospective trial.

2 Prior to collecting data, the study was reviewed and approved by the Institutional Review Board at Georgetown University Medical Center.

\section{References}

Alan Guttmacher Institute (AGI). 2003. In Their Own Right: Addressing the Sexual and Reproductive Health of Men Worldwide. New York: AGI.

Arévalo, Marcos, Irit Sinai, and Victoria Jennings. 2002. "Efficacy of a new method of family planning: The standard days method." Contraception 65: 333-338.

Asociación Demográfica Salvadoreña (ADS) and Institute for Resource Development/Westinghouse. 1987. Encuesta Nacional de Salud Familiar FESAL-85. San Salvador: ADS.

Asociación Demográfica Salvadoreña (ADS), Centers for Disease Control and Prevention, and United States Agency for International Development. 2004. Encuesta Nacional de Salud Familiar FESAL 2002/03. San Salvador: ADS.

Becker, Stan. 1996. "Couples and reproductive health: A review of couple studies." Studies in Family Planning 27(6): 291-306.

Drennan, Megan. 1998. "Reproductive Health: New Perspectives on Men's Participation." Population Reports, Series J, No. 46. Baltimore: Johns Hopkins School of Public Health, Population Information Program.

Foreit, James, Rebecka Lundgren, Irma Mendoza, Dolores Valmaña, and Judy Canahuati. 1998. "Estrategias para involucrar a los hombres en el cuidado de la salud reproductiva: De la administración de la granja a la administración de la familia." Documentos de Trabajo No. 10. New York: Population Council.

Fundación Salvadoreña para la Salud y Desarrollo Humano (FUSAL). 2000. Practicas de Crianza y Aprendizajes en las Zonas Rurales. San Salvador: FUSAL.

Greene, Margaret E. and Ann E. Biddlecom. 2000. "Absent and problematic men: Demographic accounts of male reproductive roles." Population and Development Review 26(1): 81-115. 
Gribble, James N. 2003. "The Standard Days Method of family planning: A response to Cairo." International Family Planning Perspectives 29(4): 188-191.

Hatcher, Robert et al. 2004. Contraceptive Technology. Eighteenth edition. New York: Ardent Media.

Kinkaid, D. Lawrence. 2000. "Social networks, ideation, and contraceptive behavior in Bangladesh: A longitudinal analysis." Social Science \& Medicine 50(2): 215-231.

Ministerio de Economía. Dirección General de Estadística y Censos. 1995. Proyecciones de Población de El Salvador a 2025. El Salvador: Gobierno de El Salvador.

Monroy, Margarita. 2000. "Study of the acceptability and feasibility of the Standard Days Method in rural communities in El Salvador." Final report. El Salvador: Institute for Reproductive Health.

Murphy, Elaine. 2004. “Organized family planning programs: A diffusion of innovations success story." Journal of Health Communications 8(6): 123-129.

Pan American Health Organization (PAHO). 2002. Programming for Male Involvement in Reproductive Health: Report of the Meeting of WHO Regional Advisers in Reproductive Health. Geneva: World Health Organization and PAHO.

Paulson, Susan and Patricia Bailey. 2003. "Culturally constructed relationships shape sexual and reproductive health in Bolivia." Culture, Health and Sexuality 5(6): 483-498.

Population Council. 1998. “Éxito de los voluntarios en la ampliación de conocimientos de los hombres respecto a la planificación familiar." Operations Research Summaries: Honduras. New York: Population Council.

PROCOSAL / Project Concern International, Instituto de Salud Reproductiva, and Georgetown University. 2000. Planificando Juntos:
Guía de Educación para la Visita Familiar. El Salvador: Project Concern Internacional.

Ringheim, Karin. 2002. "When the client is male: Client-provider interaction from a gender perspective." International Family Planning Perspectives 28(3): 170-175.

Rogers, Everett M. 1995. Diffusion of Innovations. Fourth edition. New York: The Free Press.

Sealza, Lita and Marilou Costello. 1998. "Male involvement through reproductive health awareness in Bukidnon Province, the Philippines: An intervention study." Final report. Manila: Population Council.

Skibiak, John P. 1993. "Male barriers to the use of reproductive health services: Myth or reality?" Paper presented at the annual meeting of the American Public Health Association, San Francisco, 27 October.

\section{Acknowledgments}

This research was funded by the United States Agency for International Development with the Institute for Reproductive Health, Department of Obstetrics and Gynecology at Georgetown University, Washington, DC. The authors would like to acknowledge the commitment to innovation and service demonstrated by the PCI/PROCOSAL staff and community volunteers and particularly to acknowledge the leadership of América de Duarte, health project coordinator. They also express gratitude to the men and women who generously shared their opinions and experiences with them during the course of the study. The authors also thank Victoria Jennings, Mihira Karra, Amy Leonard, Harris Solomon, and Muhiuddin Haider for their helpful comments in the preparation of this article. 